\title{
Consuming Dance: Choreography and Advertising by Colleen Dunagan. 2018. Oxford: Oxford University Press. 264 pp.48 screen stills. Paperback \$29.95. Hardcover \$99.00. ISBN: 9780190491376
}

Xiomara Forbez, University of California, Riverside

Keywords: advertisements, affect, dance, identity, consumers

Colleen Dunagan's monograph Consuming Dance: Choreography and Advertising explores ways in which "dance fuels advertising," By "fueling," Dunagan aptly refers to the ways in which dance serves to produce material, energy, affect, and power for advertisements. Dunagan's method focuses on descriptive analysis and close readings of 'dance-in-advertisements' ${ }^{2}$ of US products: she describes costumes, appearance of dancers and actors, mise-en-scène, actions of the camera, and choreography including facial expressions and movements of the body (at times using Laban/Bartenieff terminology and Susan Foster's definition of choreography). Products range from beverages to electronics, yet Dunagan's focus is on "the cultural and discursive work that [advertisements] do"3 and not necessarily on advertisements' effectiveness in generating profit. Consuming Dance addresses broader questions, such as: What makes dance a suitable medium for selling products? How is dance used in advertisements? How do advertisements make meaning within popular culture and lead to the constructions of consumer identities?

Consuming Dance exists as a print book and a linked companion website. The print book is divided into five chapters with a short introduction and conclusion. Black and white still images and screenshots are included alongside the text to help illustrate Dunagan's analytical points. The companion website is separated into four sections, comprising a short author biography, a book summary, an archive of advertisements (also available as a downloadable PDF), and a separate web page with links to the videos mentioned in the text. The advertisement archive includes a list with the following details: the product/brand, title, duration of advertisement (e.g. 30 seconds), year of release, producing agency, director, and choreographer/artist. Dunagan notes that the information and production credits for dancers, actors, and choreographers is limited, therefore the archive has some gaps. Nevertheless, this does not diminish the valuable contribution that this web archive provides for the field. The video section of the companion website is divided according to the book chapters, with links to YouTube versions of the advertisements discussed in the text. It is helpful to watch the videos 
before or after the reading of her analysis, though Dunagan's descriptions and close readings are vivid, detailed, and provide plenty of information. She points out that there are many possible readings for these advertisements, thus leaving space for the reader to consider other interpretations.

In Chapter 1, Dunagan lays out the theoretical foundation for her analytical work, drawing on different theories of affect, kinesthesia, kinesthetic empathy, enaction, cognition, dance, and relational aesthetics. She argues that dance is used in advertisements because it produces affect, or feeling, that can be transmitted across bodies, spaces, and times. Advertisements use dance as spectacle to draw on notions of excess. The excess allows for "dance [to] align the body's potential for movement with agency, giving form to our ability to affect and be affected by the world". ${ }^{4}$ Dance in advertisements then acts as a way of capitalizing on potentiality: "through movement's rhythm and flow, advertising taps into this potential to affectively and effectively link products and brands to the lived experience of consumers". ${ }^{5}$ This chapter highlights the power of dance to create feeling in those watching it and to connect people, experiences, and products. Building on this conceptual base, Chapter 2 provides an analysis of aesthetic conventions used in advertising, including borrowing from other "television and film genres." Dunagan distinguishes between advertisements and 'advertisements in disguise, ${ }^{7}$ or advertisements that use other genre conventions to mask their "agenda" ${ }^{8}$ as commercials. The dancing in these advertisements, along with "the incorporation of choreographic, filmic, and theatrical conventions," helps them to cross into and become akin to musicals, performances, music videos, or works of screendance and film. ${ }^{9}$ The merging of these conventions is a way for advertisements to enter into the realm of popular culture and exist as products themselves. Dunagan explains that by having advertisements operate as mechanisms for selling, entertainment, and cultural products, more entry points are created to reach as many consumers as possible.

After establishing the context of popular culture, Chapter 3 shows how dancing in advertisements may create new meanings via "correspondence to and difference from prior cultural products". ${ }^{10}$ Here Dunagan uses a Volkswagen 2005 campaign as an example because the advertisement parodies Singin' in the Rain (1952), ${ }_{1}^{11}$ but clarifies that parodic commercials are not necessarily derisive, but rather nostalgic. Dancing bodies are thus able to reference the past while still being in the present. In turn, such an approach encourages consumers to interact with advertisements as active spectators who interpret these new meanings as connected to the present, as well as referents of earlier, culturally significant moments. Chapter 4 then discusses how, in creating new meanings, advertisements are also complicit in the commodification of culture-by turning landmark events into products, they encourage forms of crosscultural appropriations. This process produces the "colonial consumer;" ${ }^{\prime 2}$ one who 
operates with white privilege to use any and all cultural artefacts for personal consumption.

In the final Chapter 5 Dunagan explains how consumption consequently becomes an act of identity formation, whereby dance serves to blur the line between spectacle and everyday life. In such developments, identity and subjectivity are performed, flexible, and accessible to anyone who consumes the right products. Dunagan argues that dance in advertisements promotes "consumption as performance of identity" while also claiming identity as a static marker of authenticity. ${ }^{13}$ In other words, even as advertisements promote identity as a performance open to "anyone," they still often ascribe and use stereotypes to sell certain "authentic" ways of being. ${ }^{14}$ After her indepth analysis of the ways in which dance fuels advertisements, Dunagan's conclusion signals new avenues for analytical exploration. She calls for "a comprehensive examination of dancers' and choreographers' bodily labor in relation to capitalism," thus highlighting a rich line of inquiry for future scholars of dance, advertising and, more broadly, of popular culture. ${ }^{15}$

Consuming Dance is important because, as the title implies, the consumption of advertisements and the products they sell, results in dance also being consumed and further incorporated into bodies, popular culture, and society, and within US neoliberal capitalist frameworks. Dunagan's discussions about the role and function of cultural and labor appropriation in advertisements, particularly through dance, are vital in conversations about the propagation of dance in consumer industries. In this respect, it would be interesting to hear more about the particular manners in which dance is being appropriated to sell specific products. Dunagan's work, therefore, prompts further questions, such as: How does dance help to sell a beverage versus a piece of clothing? How does dance in advertisements for US products reveal and produce "Americanness" and US national identity?

At the intersections of media and culture studies, dance studies, marketing and advertising, and screen/film/digital studies, Consuming Dance provides a valuable and exciting exploration of dance-in-advertisements, especially for scholars and students, as well as for those interested in popular culture, affect theory, concepts of identity-asperformance, and neoliberal capitalism and consumerism. With digital consumption of dance increasingly prevalent and accessible, this book's release in 2018 is particularly timely and relevant. Dunagan provides readers with different tools and interpretations to interact with advertisements as products in and of themselves, proposing various ways through which dance is constituent and complicit in advertisements, popular culture, and in our everyday lives. 


\section{Biography}

Xiomara Forbez is a Ph.D. Candidate in Critical Dance Studies at the University of California, Riverside. Her dissertation research includes the intersections and negotiations of dance, space, and identity, focusing particularly on the technique and training of amateur and nonprofessional dancers in ballet, bachata, and hula. Prior to graduate school, she completed her B.A. in Linguistics and French Language and Literature at Boston University and then proceeded to work in Research Administration for four and a half years. When not dancing or dissertating, Xiomara can be found watching movies, dreaming of travel, and crafting.

Email:xforb001@ucr.edu

\section{Notes}

${ }^{1}$ Colleen Dunagan, Consuming Dance, 4.

${ }^{2}$ Idem, 13.

${ }^{3}$ Idem, 11.

${ }^{4}$ Idem, 20.

${ }^{5}$ Idem, 26.

${ }^{6}$ Idem, 13.

${ }^{7}$ Ibid.

${ }^{8}$ Ibid.

${ }^{9}$ Idem, 87.

${ }^{10}$ Idem, 116.

${ }^{11}$ Singin' in the Rain, Donen and Kelly.

${ }^{12}$ Dunagan, 123.

${ }^{13}$ Idem, 173-174.

${ }^{14}$ Idem, 174.

${ }^{15}$ Idem, 197. 


\section{References}

Dunagan, Colleen. Consuming Dance: Choreography and Advertising. Oxford: Oxford University Press, 2018. https://doi.org/10.1093/oso/9780190491369.001.0001

Singin' in the Rain. Dir. Stanley Donen and Gene Kelly. 1952. Film. 